\title{
Preparation and Properties of Clay-Reinforced Epoxy Nanocomposites
}

\author{
Kusmono, ${ }^{1}$ M. W. Wildan, ${ }^{1}$ and Z. A. Mohd Ishak ${ }^{2}$ \\ ${ }^{1}$ Department of Mechanical and Industrial Engineering, Faculty of Engineering, Gadjah Mada University, \\ Jln. Grafika No. 2 Yogyakarta 55281, Indonesia \\ ${ }^{2}$ School of Materials and Mineral Resources Engineering, Engineering Campus, Universiti Sains Malaysia, \\ 14300 Nibong Tebal, Penang, Malaysia \\ Correspondence should be addressed to Kusmono; kusmono72@yahoo.com
}

Received 30 May 2013; Revised 2 September 2013; Accepted 2 September 2013

Academic Editor: Haojun Liang

Copyright (C) 2013 Kusmono et al. This is an open access article distributed under the Creative Commons Attribution License, which permits unrestricted use, distribution, and reproduction in any medium, provided the original work is properly cited.

\begin{abstract}
The clay-reinforced epoxy nanocomposite was prepared by the polymerization method. The effect of clay addition on the mechanical properties of epoxy/clay nanocomposites was studied through tensile, flexural, impact strength, and fracture toughness tests. The morphology and tribology behavior of epoxy/clay nanocomposites were determined by X-ray diffraction (XRD) and wear test, respectively. The wear test was performed to determine the specific abrasion of the nanocomposites. In addition, the water absorption characteristic of the nanocomposites was also investigated in this study. XRD analysis indicated that the exfoliation structure was observed in the epoxy nanocomposites with $3 \mathrm{wt} \%$ of clay, while the intercalated structure was shown at $6 \mathrm{wt} \%$ of clay. It was found that the addition of clay up to $3 \mathrm{wt} \%$ increased the tensile strength, flexural strength, impact strength, and the fracture toughness. On the contrary, the presence of above $3 \mathrm{wt} \%$ of clay produced a reverse effect. It could be concluded that the best properties in mechanical, wear resistance, and water resistance were obtained for the epoxy nanocomposites containing $3 \mathrm{wt} \%$ of clay.
\end{abstract}

\section{Introduction}

Polymer/clay nanocomposites (PCNs) are new class of composite materials, in which clay as a layered silicate is dispersed in nanoscale size in a polymer matrix [1]. Recently, PCNs have attracted significant academic and industrial interest. This interest stems from the fact that nanosized-layer-filled polymers can exhibit dramatic improvements in mechanical and thermal properties at low clay contents because of the strong synergistic effects between the polymer and the silicate platelets on both the molecular and nanometric scales. The potential properties enhancements of PCNs have led to increased application in various fields such as the automobile industry (exterior and interior body parts and fuel tanks), packaging industry (bottles, containers, and plastic films), electronic industry (packaging material and exterior parts of electronic devices), coating industry (paints, wire enamel coatings, etc.), and aerospace industry (body parts of airplane and exterior surface coatings).
Epoxy resins have been widely used as impregnating materials, adhesives, or matrices for composites because of their good electric insulating, good chemical resistance, low shrinkage during cure, good thermal characteristics, and ease in processing. However, the major problems with the epoxy resins for engineering applications are their low stiffness and strength when compared with metals. One effective method for offsetting these deficiencies of pure epoxy is incorporation of reinforcing fillers. Montmorillonite (MMT) clay has been well documented as the best reinforcement materials for polymer nanocomposites due to its high aspect ratio, low cost, and the fact that it consists of layered silicates which can be inserted individually in nanosize by polymer chains [2].

The dispersion of clay particles in a polymer matrix results in the formation of three types of composite materials [3]. The first type is conventional phase separated composites in which the polymer and the inorganic host remain immiscible resulting in poor mechanical properties of the 
composite material. The second type is intercalated polymerclay nanocomposites, which are formed by the insertion of one or more molecular chains of polymer into the interlayer or gallery space. The last type is exfoliated or delaminated polymer-clay nanocomposites, which are formed when the clay nanolayers are individually dispersed in the continuous polymer matrix. Exfoliated polymer-clay nanocomposites are especially desirable for improved properties because of the large aspect ratio and homogeneous dispersion of clay and huge interfacial area (and consequently strong interaction) between polymer chains and clay nanolayers.

Most important factors for success in preparing epoxy/clay nanocomposites are types of epoxy resin and curing agent/hardener used. Epoxy/clay nanocomposites based on diglycidyl ether of bisphenol A (DEGBA) resin have been synthesized using a wide range of curing agents including triethylenetetramine (TETA) [4], diaminodiphenyl methane (DDM) [5], diaminodiphenylsulfone (DDS) [6], and diethyltoluenediamine (DETDA) [7]. However, studies on the synthesis of epoxy/clay nanocomposites based on DEGBA resin with a curing agent of polyaminoamide have not yet been investigated.

The epoxy/clay nanocomposites using a type of epoxy resin of DEGBA and polyaminoamide as hardener were prepared by using an in situ polymerization method. The effect of clay addition to the neat epoxy on the tensile strength, flexural strength, impact strength, fracture toughness, and specific abrasion was investigated in this work. The dispersion of clay particles in the neat epoxy matrix was determined by using X-ray diffraction (XRD), whereas the fracture surface was studied using scanning electron microscopy (SEM).

\section{Materials and Methods}

2.1. Materials. The epoxy resin used as the matrix was DER 331, a bisphenol A diglycidyl ether-based resin (DGEBA) supplied by Dow Chemical. This epoxy resin offers epoxide equivalent weight of 182-192, viscosity of $11000-14000 \mathrm{mPa} \cdot \mathrm{s}$, and density of $1.16 \mathrm{~g} / \mathrm{cm}^{3}$ at $25^{\circ} \mathrm{C}$. Polyaminoamide purchased from PT. Justus Kimiaraya, Semarang, Indonesia, was used as the curing agent/hardener. The montmorillonite (MMT) clay (Nanomer 1.28E) was an organosilicate modified by quaternary trimethylstearylammonium ions having an approximate aspect ratio of 75-120, purchased from Nanocor Co., USA.

2.2. Preparation of Epoxy/Clay Nanocomposites. Firstly, the clay was dried in an oven at $80^{\circ} \mathrm{C}$ for 8 hours to remove water. The epoxy resin and clay were mixed with clay varied from $0,2,3,4,5$, and $6 \mathrm{wt} \%$ of clay content at $75^{\circ} \mathrm{C}$ for 2 hours using mechanical stirrer. This mixture then was degassed by a vacuum oven for 15 minutes. The curing agent of polyaminoamide was added to the mixture of epoxy/clay, mixed at $75^{\circ} \mathrm{C}$ for 5 minutes, and degassed in a vacuum oven for 3 minutes. The mixture of epoxy, clay, and curing agent was poured into the steel mold and then degassed in a vacuum oven for 10 minutes. All samples were cured in an oven at $80^{\circ} \mathrm{C}$ for 2 hours, followed by postcuring at $150^{\circ} \mathrm{C}$ for 2 hours.

\subsection{Characterization and Mechanical Properties}

2.3.1. XRD Analysis. X-ray diffraction (XRD) measurements were made directly from clay powder. In the case of the epoxy/clay nanocomposites, the measurements were carried out on bars. All these experiments were performed in reflection mode using $\mathrm{X}$-ray diffractometer at a scan rate of $0.3^{\circ} / \mathrm{min}$ in a $2 \theta$ range of $2-10^{\circ}$ and operated at $30 \mathrm{kV}$ and $20 \mathrm{~mA}$.

2.3.2. Water Absorption Test. Specimens (tensile bars) were dried at $80^{\circ} \mathrm{C}$ in an oven until a constant weight was attained prior to immersion in deionized water at room temperature. Weight gains were recorded by periodic removal of the specimen from water bath and weighing on a balance. The percentage gain at any time $t, M_{t}$ as a result of water absorption was determined by

$$
M_{t}(\%)=\frac{\left(W_{w}-W_{d}\right)}{W_{d}} \times 100 \%,
$$

where $W_{d}$ and $W_{w}$ denote, respectively, weight of dry samples (the initial weight of samples prior to immersion in deionized water) and weight of samples after exposure to deionized water.

\subsubsection{Mechanical Properties}

(1) Tensile, Flexural, and Specific Abrasion Tests. Tensile strength was measured by means of tensile test according to ASTM D638 M using a universal testing machine (Servopulser, Shimidzu). Tensile test was performed at a crosshead speed of $10 \mathrm{~mm} / \mathrm{min}$. Flexural strength was evaluated through flexural test by a universal testing machine (Torsee's) using three-point bending configuration according to ASTM D790 at a crosshead speed of $10 \mathrm{~mm} / \mathrm{min}$. Impact test was carried out on notched specimens to determine impact strength using a pendulum hammer impact test according to ASTM 256-02. Specific abrasion was measured by wear test using a universal wear machine (Riken-Ogosis).

(2) Fracture Toughness Test. A single-edge-notch 3-pointBending (SEN-3PB) test was conducted to obtain the critical stress intensity factor toughness $\left(K_{\mathrm{IC}}\right)$ of epoxy/clay nanocomposites according to ASTM D5045-96 standard using a universal testing machine (Torsee's). Rectangular specimens (thickness $6.35 \mathrm{~mm}$, width $12.70 \mathrm{~mm}$, span length $50 \mathrm{~mm}$, and overall length $56 \mathrm{~mm}$ ) were cut using a vertical band saw as shown in Figure 1. The notches were made first by the formation of saw-cut slots having rectangular shape with a width of $\sim 1 \mathrm{~mm}$ in the midsection of specimens and then by sharpening with a fresh razor blade. The total notch length of SEN-3PB specimen was $5.5 \mathrm{~mm}$ deep. The fracture toughness test was performed on a universal testing machine (Servopulser, Shimadzu EFH-EB20-40L) at crosshead speed of $10 \mathrm{~mm} / \mathrm{min}$. The load-displacement curves were recorded 


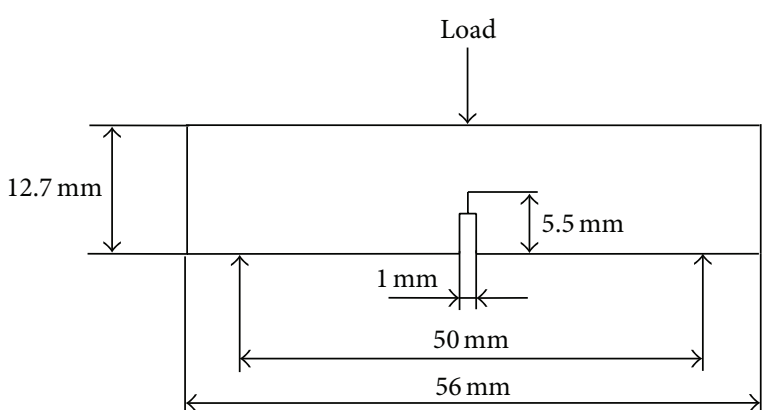

Figure 1: SEN-3PB specimen geometry used for the fracture toughness test.

and the maximum loads upon fracture were used to determine the $K_{\mathrm{IC}}$ value, which is defined by [8]

$$
K_{\mathrm{IC}}=Y \frac{3 P S \sqrt{a}}{2 B W^{2}}
$$

where $Y$ is the shape factor, $P$ is the maximum load, $S$ is the length of the span, $B$ is the specimen thickness, $W$ is the specimen width, and $a$ is the total notch length (produced by saw and fresh razor blade). For specific specimen geometry, the shape factor can be determined by the following equation

$$
\begin{aligned}
Y= & 1.93-3.07\left(\frac{a}{W}\right)+14.53\left(\frac{a}{W}\right)^{2} \\
& -25.11\left(\frac{a}{W}\right)^{3}+25.8\left(\frac{a}{W}\right)^{4} .
\end{aligned}
$$

2.3.4. Scanning Electron Microscopy (SEM). The fracture surface of SEN-3PB specimens of epoxy/clay nanocomposites was investigated using SEM (JEOL SEM) at an acceleration voltage of $12 \mathrm{kV}$. The fracture surface was sputter-coated with a thin gold-palladium layer in a vacuum chamber for conductivity before examination.

\section{Results and Discussion}

3.1. XRD Analysis. It was well known that the structure of polymer/clay nanocomposites has typically been established using X-ray diffraction (XRD) analysis and transmission electron microscopy (TEM) observation. Due to its easiness and availability, XRD is the most commonly used tool to probe the nanocomposite structure. By monitoring the position, shape, and intensity of the basal reflections from the distributed silicate layers, the nanocomposite structure (intercalated or exfoliated) may be identified. In an exfoliated nanocomposite, the extensive layer separation associated with the delamination of the original silicate layers in the polymer matrix results in the eventual disappearance of any coherent $\mathrm{X}$ ray diffraction from the distributed silicate layers. On the other hand, for intercalated nanocomposites, the finite layer expansion associated with the polymer intercalation results in the appearance of a new basal reflection corresponding to the larger gallery height.

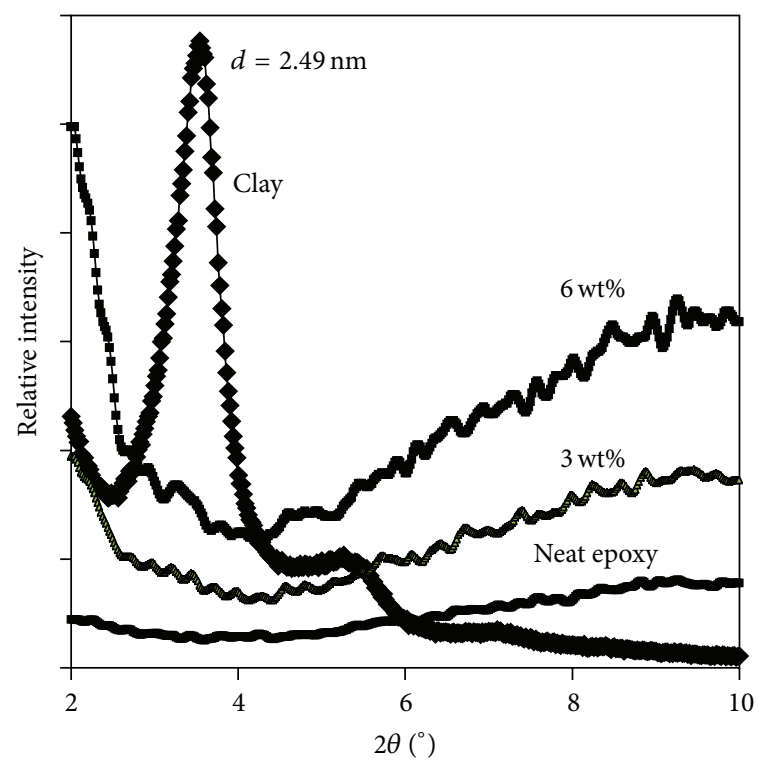

FIGURE 2: XRD patterns of neat epoxy and its nanocomposite with 3 and $6 \mathrm{wt} \%$ of clay.

Figure 2 presents the XRD patterns of clay, neat epoxy, and the epoxy nanocomposites containing 3 and $6 \mathrm{wt} \%$ of clay. For clay, the sharp peak at $2 \theta=3.54^{\circ}$ ( $d$-spacing $=$ $2.49 \mathrm{~nm}$ ) is assigned to the (001) basal plane, which corresponds to an interlayer spacing of the clay. The absence of sharp peak in the epoxy nanocomposite with $3 \mathrm{wt} \%$ of clay suggests the formation of an exfoliated structure after in situ polymerization [7]. It means that the exfoliated nanocomposite was obtained for a system with $3 \mathrm{wt} \%$ of clay. In terms of intensity of the XRD pattern for below $2 \theta=4$, the epoxy nanocomposite with $6 \mathrm{wt} \%$ of clay showed higher intensity compared to the system with $3 \mathrm{wt} \%$ of clay. This indicated that the intercalated structure or agglomerated of clay may be formed in the epoxy nanocomposite with $6 \mathrm{wt} \%$ of clay.

3.2. Water Absorption. Figure 3 shows the percentage of water absorbed by the neat epoxy and its nanocomposites with different clay content as a function of immersion time. A similar behavior for all samples was observed, where the water uptake increased rapidly during the initial stage (about 1-20 days) and then leveled off. After about 131 days, the water uptake approached a maximum value, known as the saturate point. From Figure 3, it can be seen that the epoxy nanocomposite containing $3 \mathrm{wt} \%$ of clay exhibited the lowest value in the saturated amount of absorbed water, that is, $1.48 \%$, indicating the best barrier properties. The exfoliated structure as previously discussed in XRD results may be believed to be responsible for the lowest saturated amount of absorbed water in the epoxy nanocomposite with $3 \mathrm{wt} \%$ of clay. In the exfoliated structure, the silicate layers of clay dispersed in the nanometer in a polymer matrix can create a tortuous pathway for water molecules to diffuse into the composites [9]. Vlasveld et al. [10] reported that the speed of 


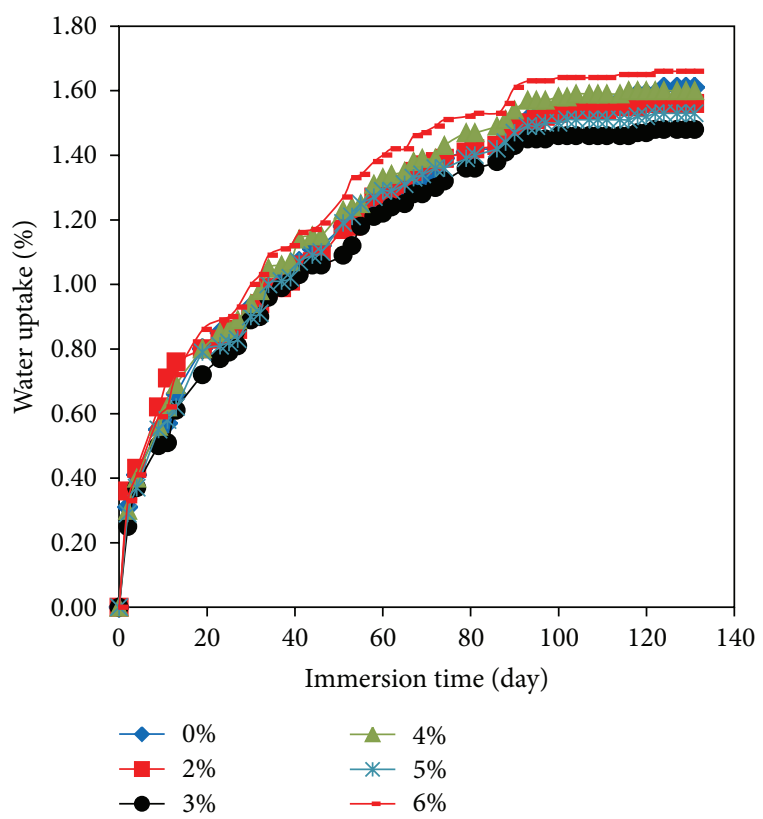

FIGURE 3: Water uptake of neat epoxy and its nanocomposites with different clay content as a function of immersion time.

moisture absorption in the polyamide 6/clay nanocomposites was reduced with increasing amounts of exfoliated silicate, due to barrier properties. Because of the high aspect ratio and large surface area of the exfoliated silicate layers, the silicate layers acted as efficient barriers against transport through the material. Several studies showed that the maximum water absorption of a polymer system decreased due to the presence of nanofiller [3,11]. Becker et al. [11] reported a reduction in maximum water uptake for different types of epoxy systems reinforced with layered silicate. On the other hand, the highest saturated amount of absorbed water was obtained for the nanocomposite with $6 \mathrm{wt} \%$ of clay. This may be attributed to the intercalated silicate layers of clay which lead to the decrease in the tortuosity effect in the nanocomposite with $6 \mathrm{wt} \%$ of clay. The diffusivity value of the exfoliated nanocomposites was lower than that of intercalated nanocomposites based on a polyamide 6/clay system.

3.3. Mechanical Properties. Figure 4 shows the effect of clay addition on the tensile strength of epoxy nanocomposites. It can be seen that the presence of clay up to $3 \mathrm{wt} \%$ has increased the tensile strength of the neat epoxy. However, beyond $3 \mathrm{wt} \%$ of clay, the addition of clay resulted in a drastic reduction in the tensile strength. In this study, the optimum clay loading was obtained at $3 \mathrm{wt} \%$. It is interesting to note that the presence of $3 \mathrm{wt} \%$ of clay has improved significantly the tensile strength by $41 \%$. The increase in tensile strength may be attributed to the formation of exfoliated structure for epoxy nanocomposites with 2 and $3 \mathrm{wt} \%$ of clay. This result is attributed to the XRD result as previously mentioned. In the exfoliated structure, individually silicate layers in nanometer size are dispersed uniformly in the polymer matrix with

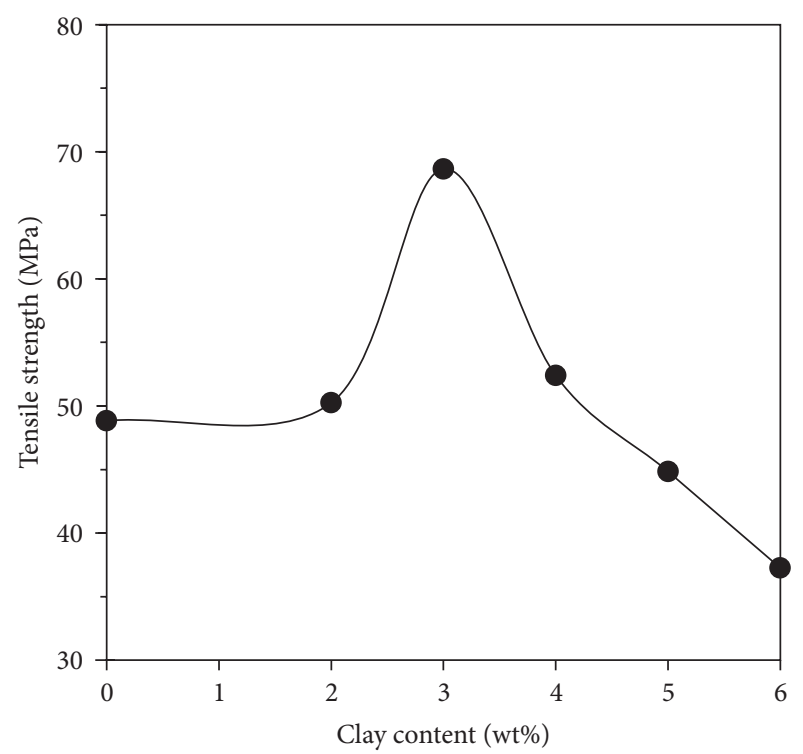

FIGURE 4: Effect of clay content on tensile strength of epoxy/clay nanocomposites.

high aspect ratio. The high aspect ratio of nanoclay may also increase the tensile strength by increasing the nanofiller contact surface area on the polymer matrix. Large numbers of reinforcing nanoclay platelets presented in the polymer matrix act as efficient stress transfer agents in the nanocomposites, inducing plastic deformation into the base polymer, and finally increase the tensile strength [12]. Furthermore, the intercalated structure or agglomerated clay particles that occurred for the epoxy nanocomposites with high clay content (above $3 \mathrm{wt} \%$ ) was believed to be responsible for the decrease in tensile strength. This intercalation structure leads to low aspect ratio of clay platelets and low contact surface area, resulting in weak adhesion between polymer matrix and clay, in which subsequently lower their tensile strength. In addition, this behavior was probably attributed to the filler-filler interaction which resulted in agglomerates, induced local stress concentration, and finally reduced tensile strength of the nanocomposites. Similar results were found by several previous researchers. Zhang et al. [13] reported that the tensile strength was increased by the addition of up to $3 \mathrm{wt} \%$ and however decreased for above $3 \mathrm{wt} \%$ of clay content for epoxy/clay nanocomposites with DEGBA resin and a curing agent of tetrahydro acid anhydride. The presence of $3 \mathrm{wt} \%$ of clay resulted in an improvement in tensile strength by $20.1 \%$. Wang et al. [6] found that the tensile strength was increased by $25 \%$ with addition of $2 \mathrm{wt} \%$ of clay, but dropped with further increasing of clay content for the epoxy/clay nanocomposites using DEGBA resin and a curing agent of DDS.

The effect of clay addition on the flexural strength of epoxy nanocomposites is presented in Figure 5. A similar behavior to that of the tensile strength was observed. The introduction of clay up to $3 \mathrm{wt} \%$ improved the flexural strength and however above $3 \mathrm{wt} \%$ of clay content reduced 


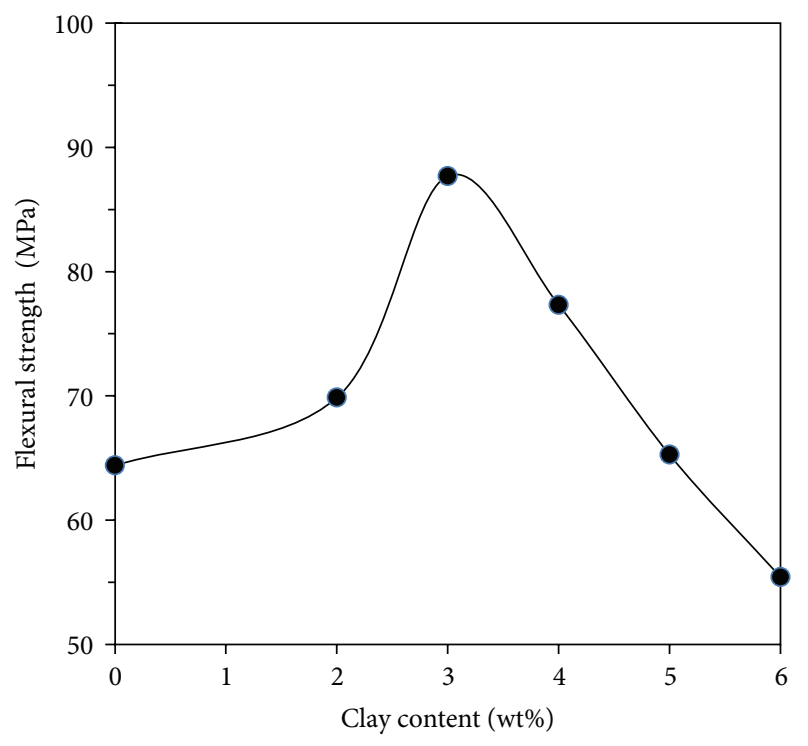

Figure 5: Effect of clay content on flexural strength of epoxy/clay nanocomposites.

the flexural strength. The exfoliated structure observed for the nanocomposites containing up to $3 \mathrm{wt} \%$ of clay content is believed to be responsible for the observed trend. In the exfoliated nanocomposites, the interfacial bonding between the nanoclay filler and the epoxy matrix is improved, thus increasing the surface area of matrix/nanoclay interaction. As a result, this leads to good stress transfer from the matrix to the nanoclay, thus resulting in improved flexural strength [14]. The decrease in flexural strength above $3 \mathrm{wt} \%$ of clay content was probably due to the presence of agglomerated clay particles, which possibly acted as stress concentration sites and caused a decrease in the flexural strength of the nanocomposites $[15,16]$. In a similar study, Kaynak et al. [17] investigated the flexural strength of nanoclay (Na-montmorillonite) based epoxy nanocomposites. Results showed an improvement in flexural strength and fracture toughness with maximum value at $0.5 \%$ nanoclay loading due to the exfoliation structure of clay. Chow et al. [15] studied that the effect of addition of organoclay on the flexural strength in injection-molded polyamide 6/polypropylene nanocomposites. Their results showed that the flexural strength was increased with an increasing up to $4 \mathrm{phr}$ organoclay loading and, however, above $4 \mathrm{phr}$ led to reduction in flexural strength. The increase in flexural strength at up to $4 \mathrm{phr}$ organoclay loading might be attributed to the exfoliated structure. On the other hand, the intercalated or agglomerated silicate layers of clay were believed to be responsible for the decrease in flexural strength at above $4 \mathrm{phr}$.

The impact strength of epoxy nanocomposites as a function of clay content is presented in Figure 6. It is clear that the impact strength of the nanocomposites was increased with the clay content up to $3 \mathrm{wt} \%$. Beyond $3 \mathrm{wt} \%$ clay content, the impact strength was decreased drastically with the clay content in the nanocomposites. The maximum improvement

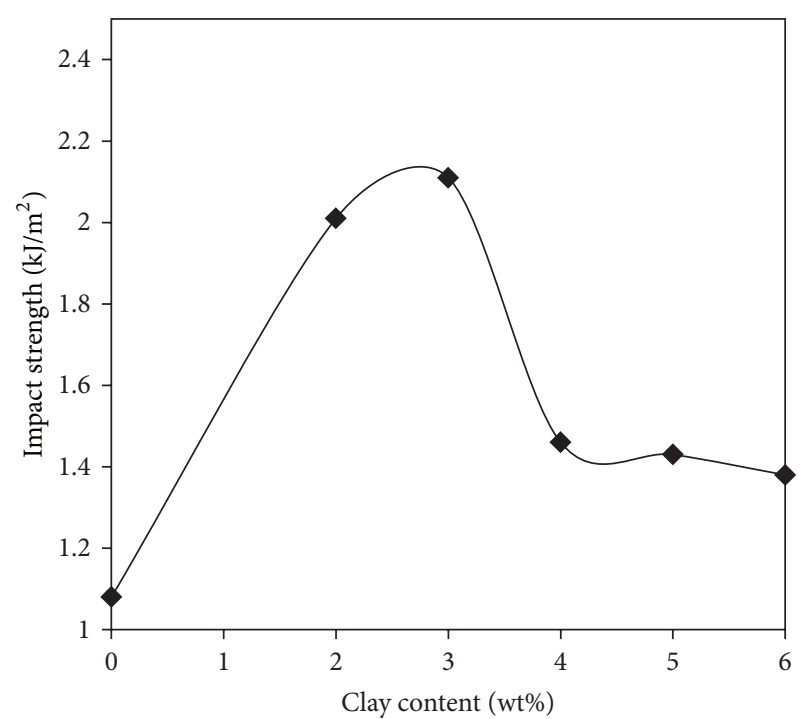

FIGURE 6: Effect of clay content on impact strength of epoxy/clay nanocomposites.

in impact strength was obtained at $3 \mathrm{wt} \%$ of clay content with increment of $95 \%$. This indicated that the clay has more effective toughening agent especially for $3 \mathrm{wt} \%$ of clay. The increase in impact strength may be related to the exfoliated silicate layers of clay in the neat epoxy matrix as shown in XRD results. In the exfoliated structure, individually silicate layers in nanometer size are dispersed uniformly in the neat epoxy matrix with high aspect ratio. The nanoclays may have a good toughening effect acting as efficient crack stoppers and form a tortuous crack propagation path resulting in higher impact strength [18]. Furthermore, the intercalated or agglomerated silicate layers of clay were believed to be responsible for the reduction in impact strength for the epoxy nanocomposites containing above $3 \mathrm{wt} \%$ of clay content. Zhang et al. [13] reported that the impact strength was improved with the presence of clay up to $3 \mathrm{wt} \%$, and beyond $3 \mathrm{wt} \%$ of clay content the impact strength was drastically reduced in the epoxy/clay nanocomposites.

The effect of clay addition on the fracture toughness of epoxy nanocomposites was shown in Figure 7. The fracture toughness of the neat epoxy was improved by the presence of clay up to $3 \mathrm{wt} \%$. However, the presence of more than $3 \mathrm{wt} \%$ of clay has made the epoxy nanocomposites more brittle. A similar trend to that of the impact strength (cf. Figure 6) was observed. The optimum toughness of the epoxy nanocomposites was achieved for the content of $3 \mathrm{wt} \%$ clay, where its improvement was $19 \%$ compared to the neat epoxy. The exfoliated structure is believed to be responsible for the improvement in fracture toughness. The individually silicate layer nanosized may be able to resist the crack propagation and finally increase the fracture toughness. At high content of clay ( $>3 \mathrm{wt} \%)$, the agglomerated clay particles may act as initial crack and then reduce the fracture toughness. Liu et al. [19] investigated the effect of clay addition on the fracture toughness for epoxy/clay 


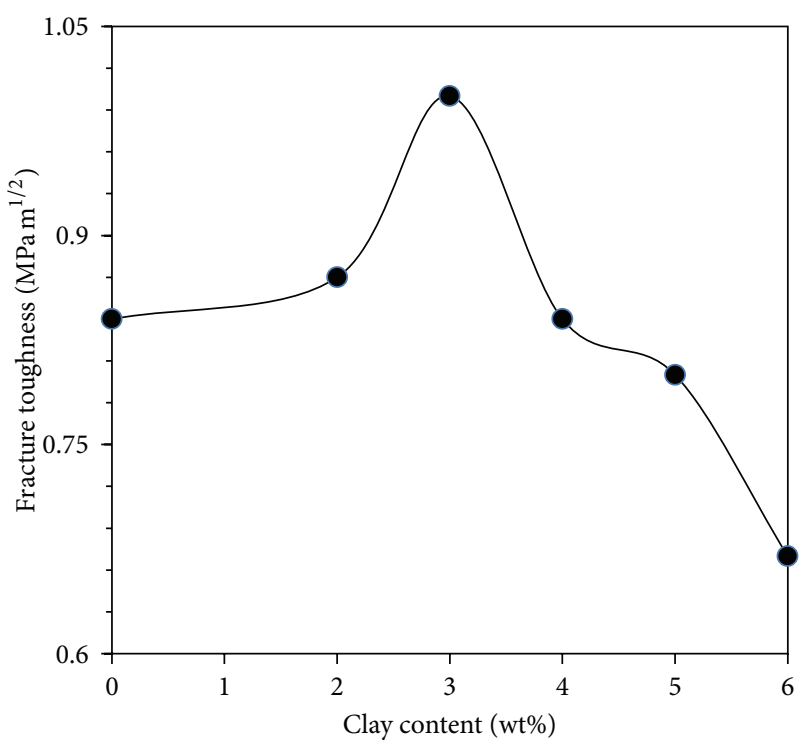

FIGURE 7: Effect of clay content on fracture toughness of epoxy/clay nanocomposites.

nanocomposites using epoxy resin type of tetraglycidyl4,4-diaminodiphenylmethane (TGDDM) cured with DDS. They reported that the fracture toughness based on value measurement of critical stress intensity factor $\left(K_{\mathrm{IC}}\right)$ and critical energy release rate $\left(G_{\mathrm{IC}}\right)$ was dramatically increased by the addition of up to $4.5 \mathrm{wt} \%$ of clay due to the better clay dispersion. However, the fracture toughness was decreased with further increasing of clay content. Wang et al. [6] studied the fracture toughness of nanocomposites based on DEGBA epoxy resin and a curing agent of DDS. They found that the $K_{\mathrm{IC}}$ and $G_{\mathrm{IC}}$ values were improved by $77 \%$ and $190 \%$ for $2 \mathrm{wt} \%$ of clay content, respectively. However, the fracture toughness was reduced with further addition of clay.

Figure 8 shows the specific abrasion of epoxy nanocomposites as function of clay loading. It was found that the addition of clay up to $3 \mathrm{wt} \%$ has reduced drastically the specific abrasion of the neat epoxy. On the other hand, the more addition of clay has improved the specific abrasion. The characteristic of structure in the nanocomposites may be attributed to the behavior of the specific abrasion of the epoxy nanocomposites. Again, the exfoliated structure in the epoxy nanocomposites with 2 and $3 \mathrm{wt} \%$ of clay content reduced the specific abrasion. The best abrasion characteristic was also achieved for the epoxy nanocomposite with $3 \mathrm{wt} \%$ of clay. The increase in specific abrasion for the nanocomposites with above $3 \mathrm{wt} \%$ of clay content was due to the agglomerated clay particles acting as stress concentration sites and reduced the specific abrasion value.

3.4. SEM Observation. Figures 9(a) and 9(b) show the SEM micrographs of SEN-3PB fracture surface of neat epoxy composite and its nanocomposite containing $3 \mathrm{wt} \%$ of clay, respectively. From Figure 9(a), it can be seen that the neat

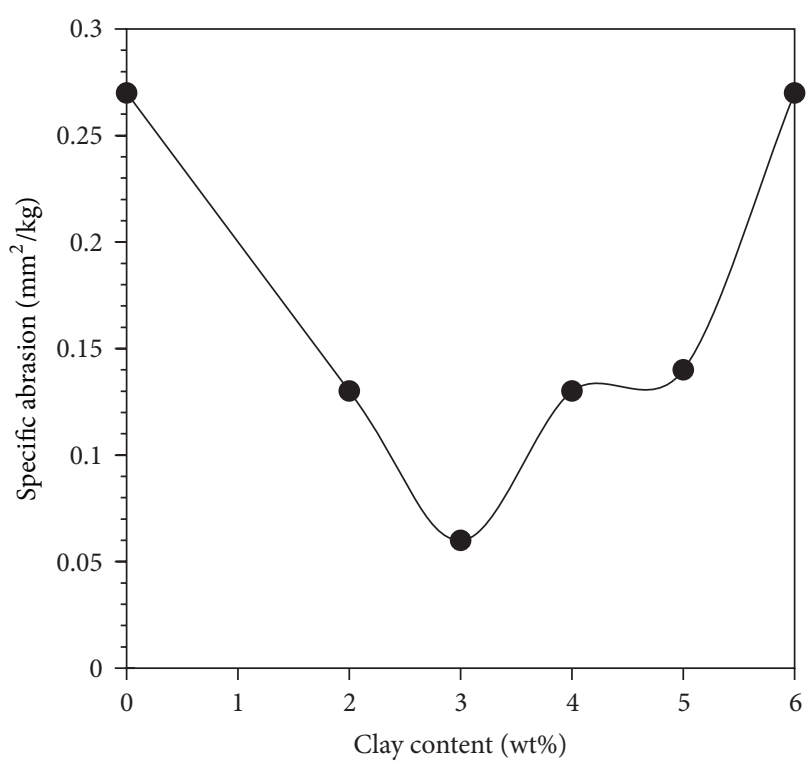

FIGURE 8: Effect of clay content on specific abrasion of epoxy/clay nanocomposites.

epoxy exhibited a relatively smooth fracture surface indicating very fast and straight crack propagation [14]. This indicates a typical fractography feature of brittle fracture behavior, thus accounting for the low fracture toughness of the neat epoxy. However, it is evident that the presence of clay in the epoxy nanocomposites with $3 \mathrm{wt} \%$ of clay increased the roughness of the fracture surfaces (Figure 9(b)). An increase in fracture surface roughness is an indicator of crack deflection mechanism, which increased the absorbed energy of fracture by increasing the crack length during deformation [14]. This confirmed a higher $K_{\mathrm{IC}}$ value for the nanocomposite with $3 \mathrm{wt} \%$ of clay than that for neat epoxy. In addition, the higher $K_{\mathrm{IC}}$ value may also be attributed to the stress disturbance caused by the clay particles. These clay particles acted as obstacles, causing the crack to take a more tortuous part, manifesting a meandering crack trajectory. Liu et al. [7] reported that more than one toughening mechanism usually occurs in the epoxy/clay system such as shear yielding of the matrix, crack deflection, micro voiding, and debonding between clay and epoxy.

\section{Conclusion}

Epoxy/clay nanocomposites were successfully prepared by using polymerization methods. The optimum properties of tensile strength, flexural strength, impact strength, fracture toughness, and specific abrasion were obtained for the epoxy nanocomposites containing $3 \mathrm{wt} \%$ of clay. The tensile strength, flexural strength, impact strength, and fracture toughness were increased by $41,20,95$, and $19 \%$, respectively. This result was attributed to the formation of exfoliation structure in the nanocomposite with $3 \mathrm{wt} \%$ of clay as indicated by the XRD pattern. 


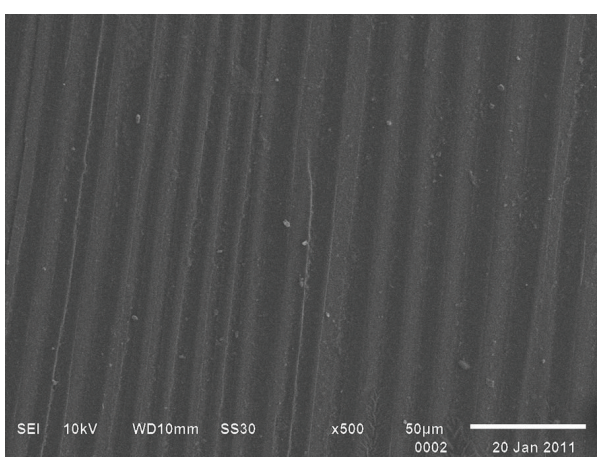

(a)

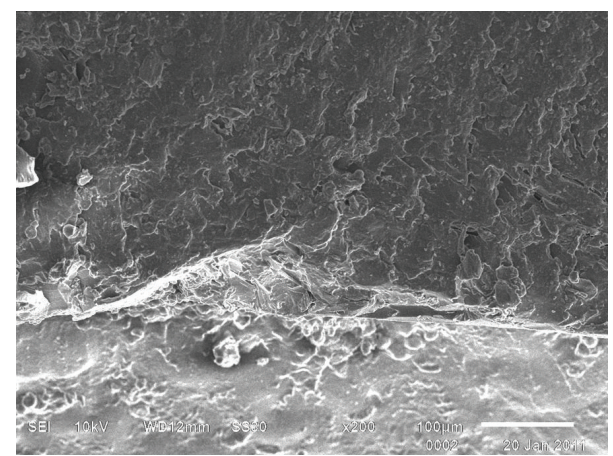

(b)

FIGURE 9: SEM micrographs of SEN-3PB fracture surface of: (a) neat epoxy. (b) Epoxy/clay nanocomposite with 3 wt\% of clay content.

\section{Acknowledgments}

The financial support of Universitas Gadjah Mada fundamental research grant (Contract no. LPPM-UGM/755/BID.I/ 2011) is very gratefully appreciated. The authors also thank Mr. Angga Zurahman and Mr. Nanang Kurnia Pradipta for their help in this work.

\section{References}

[1] S. Sinha Ray and M. Okamoto, "Polymer/layered silicate nanocomposites: a review from preparation to processing," Progress in Polymer Science, vol. 28, no. 11, pp. 1539-1641, 2003.

[2] A. Gu and G. Liang, "Thermal degradation behaviour and kinetic analysis of epoxy/montmorillonite nanocomposites," Polymer Degradation and Stability, vol. 80, no. 2, pp. 383-391, 2003.

[3] E. P. Giannelis, R. Krishnamoorti, and E. Manias, "Polymersilicate nanocomposites: model systems for confined polymers and polymer brushes," Advances in Polymer Science, vol. 138, pp. 108-147, 1999.

[4] T. P. Mohan, M. R. Kumar, and R. Velmurugan, "Rheology and curing characteristics of epoxy-clay nanocomposites," Polymer International, vol. 54, no. 12, pp. 1653-1659, 2005.

[5] V. Nigam, D. K. Setua, G. N. Mathur, and K. K. Kar, "Epoxymontmorillonite clay nanocomposites: synthesis and characterization," Journal of Applied Polymer Science, vol. 93, no. 5, pp. 2201-2210, 2004.

[6] L. Wang, K. Wang, L. Chen, Y. Zhang, and C. He, "Preparation, morphology and thermal/mechanical properties of epoxy/nanoclay composite," Composites A, vol. 37, no. 11, pp. 1890-1896, 2006.

[7] T. Liu, W. C. Tjiu, Y. Tong, C. He, S. S. Goh, and T. Chung, "Morphology and fracture behavior of intercalated epoxy/clay nanocomposites," Journal of Applied Polymer Science, vol. 94, no. 3, pp. 1236-1244, 2004.

[8] R. W. Hertzberg, Deformation and Fracture Mechanics of Engineering Materials, Wiley, New York, NY, USA, 1989.

[9] H. Zhao and R. K. Y. Li, "Effect of water absorption on the mechanical and dielectric properties of nano-alumina filled epoxy nanocomposites," Composites A, vol. 39, no. 4, pp. 602611, 2008 .
[10] D. P. N. Vlasveld, J. Groenewold, H. E. N. Bersee, and S. J. Picken, "Moisture absorption in polyamide- 6 silicate nanocomposites and its influence on the mechanical properties," Polymer, vol. 46, no. 26, pp. 12567-12576, 2005.

[11] O. Becker, R. J. Varley, and G. P. Simon, "Thermal stability and water uptake of high performance epoxy layered silicate nanocomposites," European Polymer Journal, vol. 40, no. 1, pp. 187-195, 2004.

[12] S. Parija, S. K. Nayak, S. K. Verma, and S. S. Tripathy, "Studies on physico-mechanical properties and thermal characteristics of polypropylene/layered silicate nanocomposites," Polymer Composites, vol. 25, no. 6, pp. 646-652, 2004.

[13] K. Zhang, L. Wang, F. Wang, G. Wang, and Z. Li, "Preparation and characterization of modified-clay-reinforced and toughened epoxy-resin nanocomposites," Journal of Applied Polymer Science, vol. 91, no. 4, pp. 2649-2652, 2004.

[14] H. Alamri and I. M. Low, "Microstructural, mechanical, and thermal characteristics of recycled cellulose fiber-halloysiteepoxy hybrid nanocomposites," Polymer Composites, vol. 33, no. 4, pp. 589-600, 2012.

[15] W. S. Chow, Z. A. M. Ishak, U. S. Ishiaku, J. Karger-Kocsis, and A. A. Apostolov, "The effect of organoclay on the mechanical properties and morphology of injection-molded polyamide 6/polypropylene nanocomposites," Journal of Applied Polymer Science, vol. 91, no. 1, pp. 175-189, 2004.

[16] S. Mohanty and S. K. Nayak, "Effect of clay exfoliation and organic modification on morphological, dynamic mechanical, and thermal behavior of melt-compounded polyamide- 6 nanocomposites," Polymer Composites, vol. 28, no. 2, pp. 153$162,2007$.

[17] C. Kaynak, G. I. Nakas, and N. A. Isitman, "Mechanical properties, flammability and char morphology of epoxy resin/montmorillonite nanocomposites," Applied Clay Science, vol. 46, no. 3, pp. 319-324, 2009.

[18] A. B. Inceoglu and U. Yilmazer, "Synthesis and mechanical properties of unsaturated polyester based nanocomposites," Polymer Engineering and Science, vol. 43, no. 3, pp. 661-669, 2003.

[19] W. Liu, S. V. Hoa, and M. Pugh, "Fracture toughness and water uptake of high-performance epoxy/nanoclay nanocomposites," Composites Science and Technology, vol. 65, no. 15-16, pp. 23642373, 2005. 

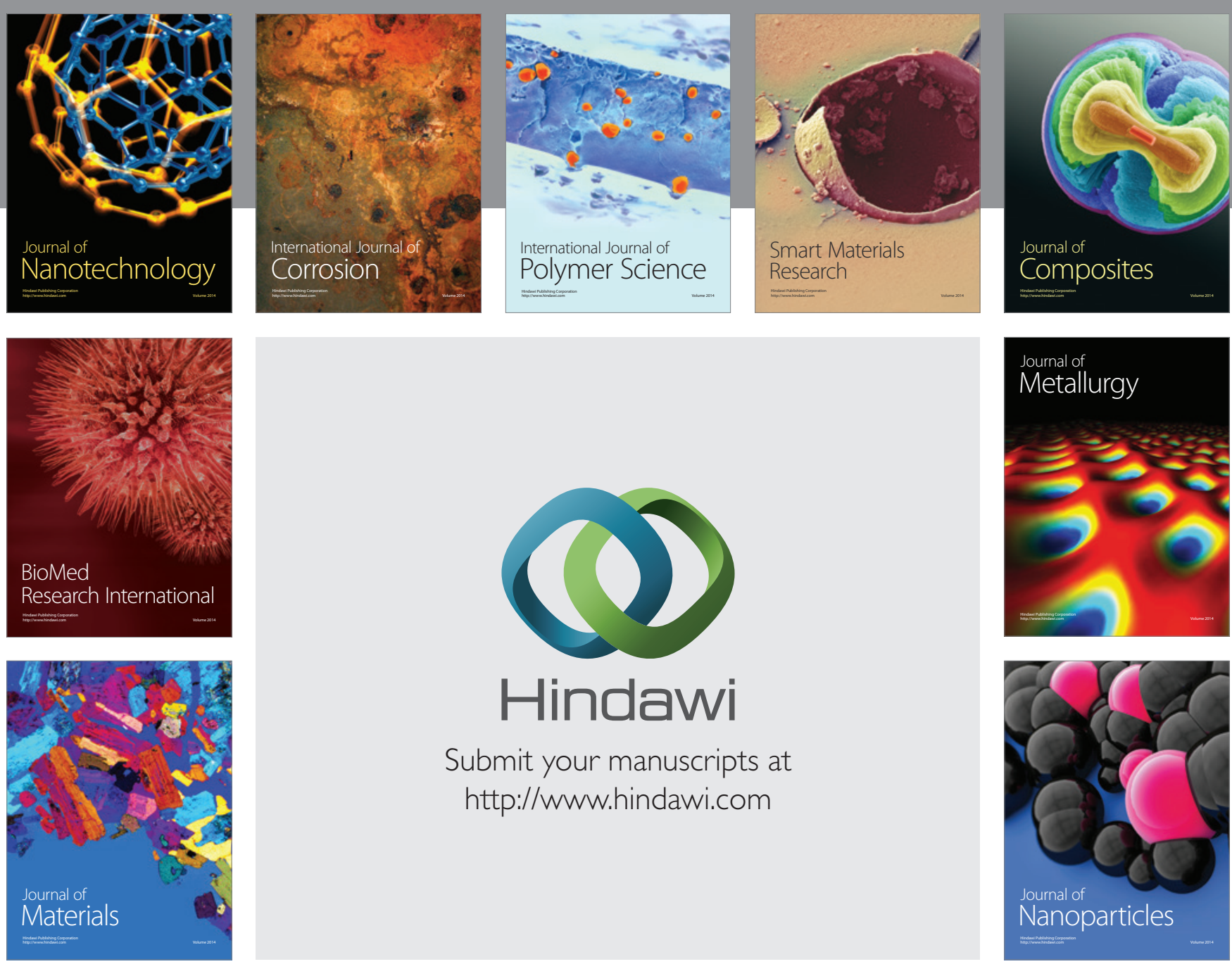

Submit your manuscripts at http://www.hindawi.com


\section{The Scientific World Journal}
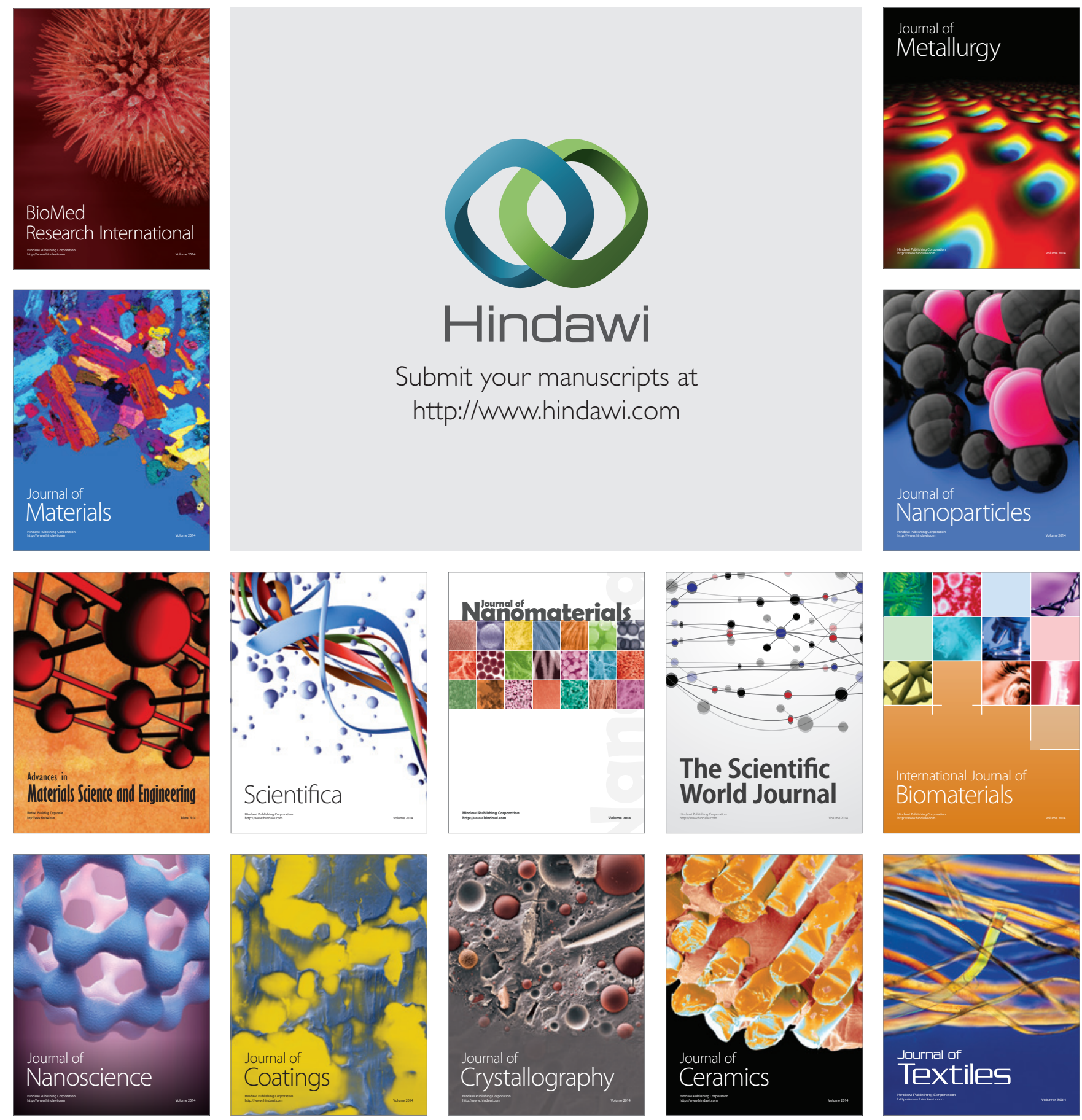